\title{
Getting People on the Job
}

\section{By R. D. Rhoades and K. E. Jacobsen}

W

hatever the future brings, firms that learn to hire talent and to retain it successfully will have a distinct advantage in the years ahead." ${ }^{1}$ Although simplistic in nature, this statement highlights the importance of identifying high-quality employees and suggests how essential human capital is if a ranch expects to achieve long-term goals. In ranching, like any profession, a certain set of skills are required for a job position. Consequently, planning is critical to ensure that the right people possessing the "right" skills are hired for that particular position. The book Good to Great recommends having the right people on the bus in the right seats, and moving the wrong people off the bus, as critical steps in moving any organization from good to great status. $^{2}$

Hiring decisions today can greatly impact the future success of a ranch; however, most ranch managers do not allow enough time to plan and anticipate the ranch's labor needs. This lack of planning can often lead to hiring a new employee as a short-term solution to an immediate need. The proper management decision would be to hire a qualified individual based on the long-term objectives of the ranch.

Locating qualified employees who possess the appropriate set of skills for a particular position can be difficult. Successful ranches have typically developed a structured plan to address this issue. A labor plan that includes anticipating future needs is as important as a well-thought-out production strategy. Planning ahead and leading your management team to anticipate its needs can be a step in the right direction toward a winning result. Table 1 illustrates a suggested list of six steps that offer some direction when developing an employment plan.

\section{Anticipate and Assess Labor Needs}

Many managers often struggle with identifying and planning when it comes to labor issues. While time may be saved in the short term by installing a quick-fix solution, the long-term ramifications of a poor initial plan to address a labor need can be a recipe for failure. Instead, future labor and leadership needs should be proactively anticipated and assessed. It is typically helpful to periodically review your leadership and staffing requirements to answer the following questions:

- Where is the ranch going?

- How many people and what positions will be needed in the next several years?
- What will the ranch's organizational structure look like and how will the needs change over time?

- What does your ranch's leadership pipeline need to contain today to ensure the development of leaders tomorrow?

First, to answer these questions, management should assess the current talent pool and then determine the ranch's current leadership and employment gaps to help define future recruiting and employee development needs. In assessing the current talent pool, management should review baseline education and experience, review work performance history, and evaluate talent for fit in future ranch positions.

The appraisal of talent for "fit" in future positions will likely prove to be the most challenging. Formal leadership assessment tools such as $360^{\circ}$ survey and Talent Plus are available to assist with such evaluations along with the experience of management in working with the employee.

Managers will often assume that current performance is the only metric equating to success at the next step. However, moving up the ladder is not always the best way to progress every employee. "Great managers select for talent, define the right outcomes, focus on strengths, and find the right fit." Management should consider formulating a succession plan to better anticipate future leadership and labor needs and identify any potential gaps in the ranch's pipeline of current talent. A simple leadership map could be drawn starting with the general manager and working down through the different layers of the management team. Next to each current ranch leader, a list of potential replacements could be created based on management's assessment of the current talent pool.

Finally, managers should consider integrating human resource management into their overall strategic planning process when anticipating and assessing labor needs. If implementing a balanced strategic planning process is the ultimate goal, the process should consider the customer, the business, and the employee. Considering employee development in the strategic planning process could lead to a more balanced plan and could help to ensure proactive recruiting and that development initiatives are being addressed by management. Anticipating future labor needs and assessing current talent are important steps when planning for the future, but they will require continuous effort in both strategic human resource management and employee development. 
Table 1. Guidelines to follow when developing a plan for getting people on the job

1. Anticipate and assess ranch labor needs

2. Define the job

3. Develop the candidate pool

4. Assess the candidates

5. Close the deal

6. Integrate the new hire

\section{Define the Job}

After labor needs are identified, it is a good idea to be specific in defining the competencies needed for the current and future job openings on your ranch. To ensure future success for the employee when initially defining the job, consider the following competencies: job-based, team-based, and organization-based. ${ }^{1}$ Job-based competencies may comprise the specific skills required for the job being offered. Some jobs may require the employee to lead a team, to staff a team, or to be a part of a team. Consequently, team-based competencies can be critical when defining a job. Team dynamics within a ranch are vital to long-term success, so when defining the job a manager should consider the current team makeup in which the candidate will work. Ranch culture can also significantly impact the long-term success of a new employee. Unique qualities needed to fit within the culture are considered to be organizationally based competencies and are also noteworthy when defining a job.

Defining a job based on the specific needs of the ranch starts with the development of a good job description. Figure 1 highlights several suggested items that need to be included in a good job description. If done correctly, a good job description can be a valuable way of facilitating communication between the employer and potential job candidates. From a management perspective, a job description should highlight expectations, essential functions, and compensation ranges. Subsequently, it should help a potential candidate recognize whether or not they are capable of performing the duties specified for the position before they apply. A good job description can also be a helpful tool for orienting and evaluating new employees once the right person is hired and progressing within the organization.

\section{Develop the Candidate Pool}

Once a quality job description has been written, the wider the net that is cast, the greater the likelihood of finding the right person for the job. Ten to twelve candidates per job offering are ideal to achieving this success. ${ }^{1}$ The reputation of the ranch will have an impact on the number of potential candidates attracted to the final job offering. If your ranch is known as a great place to work, it will have a distinct advantage when trying to attract high-quality potential employees. A reputation as a great place to work can be developed if management is willing to show their employees that they play a significant role in the overall success of the ranch and are motivated to help them succeed individually.

To cast a wider net and to attract high-quality candidates, managers should consider the concept of insiders, inside-outsiders, outside-insiders, and outsiders when developing the candidate pool. Insiders are internal candidates who work at the ranch and with whom management is already familiar. Inside-outsiders are also internal candidates that are perhaps located in a remote location, lack regular exposure to management, or to some degree have been looked over when considering candidates for the new position. Outside-insiders are former employees, customers, suppliers, advisors, or someone who has worked closely with the ranch and its current employees in the past. Outsiders are applicants that are completely unknown to management. Because developing a large pool of potential candidates is vital, considering candidates from each of these perspectives could prove to be beneficial.

There are a couple of strategies to consider when developing a pool of potential candidates for a particular job offering. If management is looking internally, the position or job description should be appropriately advertised to alert those insiders and inside-outsiders of the new or available position. Also, consider utilizing search committees for key positions or perhaps offer a recruiting bonus as an incentive for current employees to participate in the promotion of a new position. The search committee can include people from both inside and outside the ranch. Managers should also consider using internships to recruit future college graduates.

\section{Assess the Candidates}

Once the candidate pool is developed, the management team should be prepared to assess the candidates. Improving the quality of assessment can be three times more profitable than increasing the size of the candidate pool and six times more profitable than getting the selected candidate to accept a lower wage. ${ }^{1}$ Assessing the candidate is certainly not an easy task, but steps can be implemented to improve the quality of the candidate-assessment process. Table 2 contains some possible ways to do so.

First, make sure the right interviewers are conducting the candidate assessment. The best interviewers are often very familiar with the job, yet self-confident enough in their own abilities to hire the best possible candidate for the new position. Additionally, these interviewers are not threatened by someone more talented than themselves. Utilizing the wrong interviewers can yield a greater negative result than selecting from a pool of potential candidates at random.

Second, the right number of interviewers to assess the candidate should be utilized. Three independent, topcaliber interviewers should be sufficient for the core selection committee. ${ }^{1}$ The interview team should include the prospective boss, the boss's superior, and the human resource manager. 


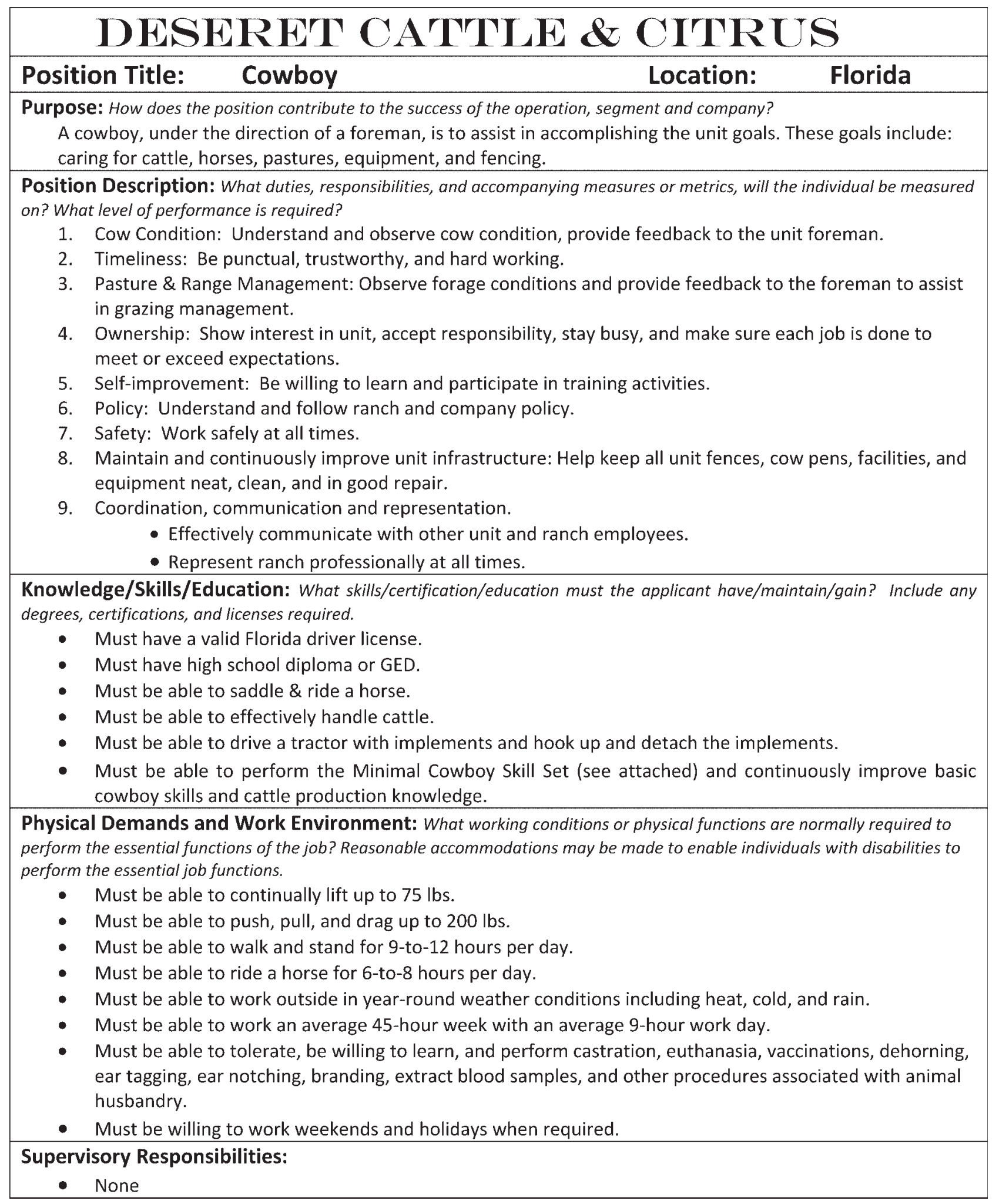

Figure 1. Example of a quality job description outlining important features to communicate when seeking ranch employees. 

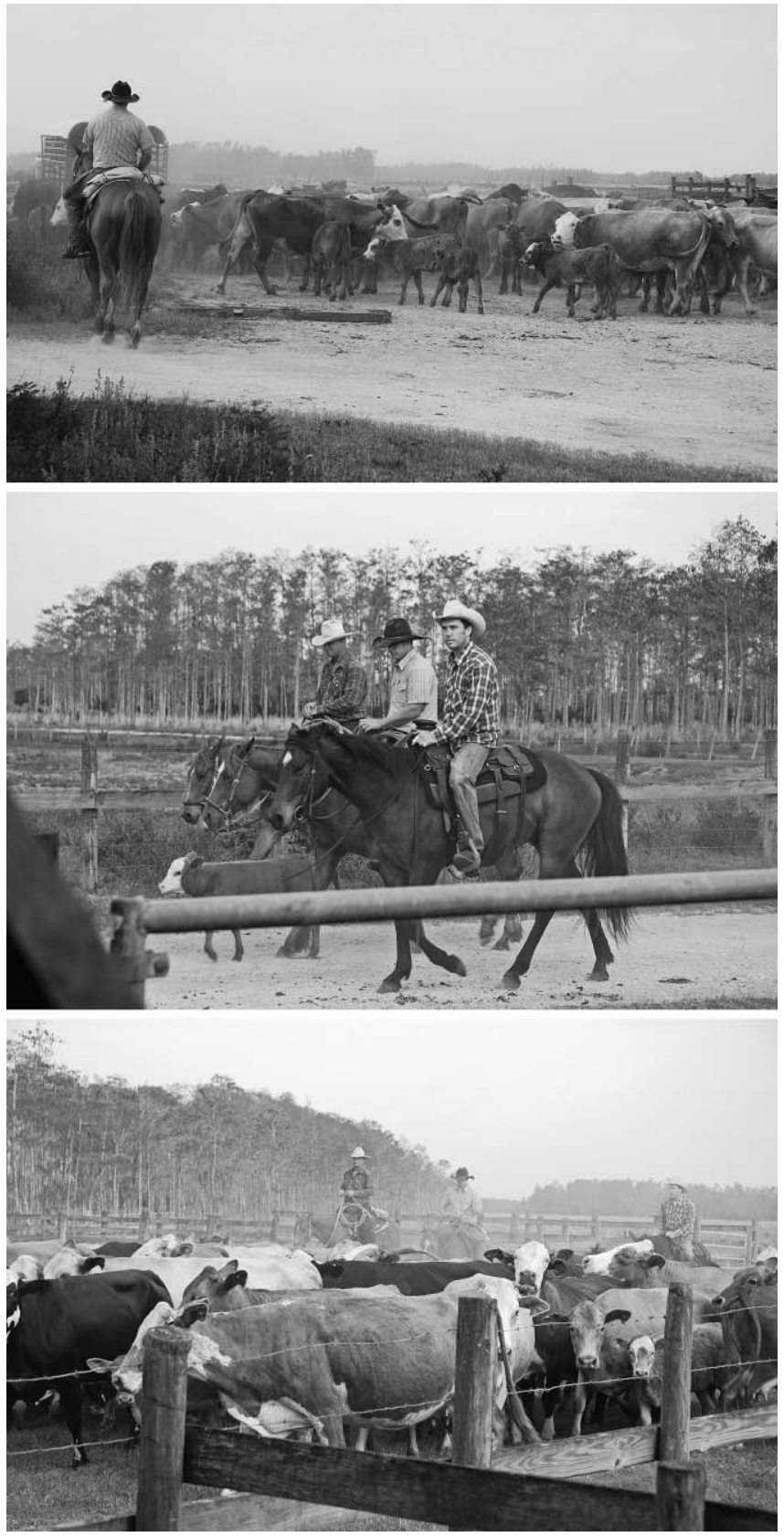

Photos courtesy of Deseret Cattle \& Citrus, St Cloud, Florida, USA.

Third, make sure the right techniques are being used when assessing the candidates. Behavioral event interviews in which the candidate is asked to describe specific experiences and results can be very effective. ${ }^{1}$ The management team should consider conducting thorough reference and background checks. Following the interviews, interviewers should meet and have a rigorous and disciplined conversation about the candidates. Interviewers should also consider using a matrix to score candidates on specific attributes.

Finally, make sure the right organizational support at the ranch is in place when assessing candidates. This may mean including other key managers and peers within the company
Table 2. Steps to improve the assessment of potential candidates for a job position

1. Have the right interviewers conduct the assessment

2. Have the right number of interviewers conduct the assessment

3. Use the right techniques to assess the candidates

4. Have the right organizational support in place when assessing the candidates

in the formal interview process. At the end of the day, the hiring manager should have the right to make the final hiring decision.

\section{Close the Deal}

Even when the hiring team has correctly assessed the candidates and has selected the right person for the job, at least one in five potential hires will be likely to turn down the job offer. ${ }^{1}$ Demonstrating the ranch's commitment and interest in the selected candidate is an important feature when attempting to close the deal. A realistic presentation of both the opportunities and challenges the position may offer the new employee is another good tactic to implement when trying to close the deal. It shows commitment from the ranch if the hiring manager makes the final offer to the selected candidate, rather than a representative from the human resource department. Additionally, when closing the deal with a prospective candidate, management should not only consider the current market rate within the ranching industry for similar positions being offered, but they should also benchmark against the current level of compensation within the ranch itself to ensure any offer made is fair to current employees.

\section{Integrate the New Hire}

Research shows that most firms do not take the appropriate steps necessary to ensure that all new employees are properly integrated into the company's culture. ${ }^{1}$ In fact, these studies suggest that one-third of employers lose between 10\% and $25 \%$ of their new employees within the first year on the job. There are a number of factors that can contribute to this lack of success between the new employee and the firm. Table 3 lists factors that might contribute to a new

Table 3. Factors that can contribute to the lack of success between the ranch and a new employee

1. Unrealistic expectations of the new employee

2. A failure to grasp task completion around the ranch

3. Poor communication with supervisor

4. A lack of understanding the link between the new employee's job and the ranch's goals and objectives 
employee's lack of success. Although not exhaustive, all of the factors presented can lead to the early departure of the employee that the ranch has invested a great deal of time, money, and effort into hiring. New-employee training programs, detailed orientation plans for higher-level positions, and mentoring cultures all help to integrate the new employee and to reduce the chances of losing them during the integration period. Utilizing veteran top performers as mentors and regularly meeting with new employees can also be effective in reducing early turnover.

\section{Summary}

A good hiring process developed by the management team can greatly reduce but can never eliminate the chances of making a hiring mistake. Finding and retaining talented individuals with the ability to advance will be critical to the long-term success of a ranch. It is a process that requires deliberate effort and well-developed plans. Great managers know that "getting the right people on the job" makes all the difference and therefore should be one of their greatest priorities.

\section{References}

1. Fernandez-Araoz, C., B. Groysberg, and N. Nohria. 2009. The definitive guide to recruiting in good times and bad. Harvard Business Review 87:74-84.

2. Collins, J. C. 2001. Good to great: why some companies make the leap and others don't. New York, NY, USA: HarperCollins Business Publishing. 300 p.

3. Buckingham, M., and C. Coffman. 1999. First break all the rules: what the world's greatest managers do differently. New York, NY, USA: Simon and Schuster. 271 p.

Authors are Assistant Professor, King Ranch Institute for Ranch Management, Texas AE'M University-Kingsville, Kingsville, TX 78363,USA,ryan.rhoades@tamuk.edu (Rhoades); and Vice President and General Manager, AgReserves, Inc., Salt Lake City, UT 84111, USA (Jacobsen). Current address for Jacobsen: Deseret Cattle E Citrus, St Cloud, FL 34773, USA. 